\title{
Research on application of Unmanned Aerial Vehicles (UAVs) in cadastral mapping of arable land
}

\author{
Quy Ngoc Bui 1, *, Tuan Anh Pham ${ }^{2}$, Quan Anh Duong 1, Hiep Van Pham 1, Kien \\ Trung Tran ${ }^{3}$, Tu Xuan Hoang ${ }^{4}$, Dong Dai Nguyen ${ }^{5}$, Duc Danh Nguyen ${ }^{1}$, Hung Viet \\ Nguyen 6 \\ 1 Faculty of Geomatics and Land Administration, Hanoi University of Mining and Geology, Vietnam \\ 2 Phu Tho Department of Natural Resouces and Environment, Vietnam \\ ${ }^{3}$ Department of Operations, General Staff of the Vietnam People's Army, Vietnam \\ ${ }^{4}$ Land survey consultant joint stock company, Vietnam \\ ${ }^{5}$ Department of Surveying and Map Vietnam, Vietnam \\ ${ }^{6}$ University of Transport and Communications, Vietnam
}

\section{ARTICLE INFO}

Article history:

Received $16^{\text {th }}$ Sept. 2020

Revised $03^{\text {rd }}$ Oct. 2020

Accepted 31st Oct. 2020

\section{Keywords:}

Arable land,

Cadastral,

UAV.

\section{ABSTRACT}

Cadastral maps are an important part of cadastral documents, they are legal component of land administration in local authorities. Traditionally, a cadastral map is established by using land surveying methods which can provide high accuracy as required. In recent years, the UAV devices are developed and can provide an accurately tool for cadastral mapping on arable lands. This paper presents an evaluation of UAV application in cadastral mapping in comparison with traditional surveying for arable land. The results show that using UAV images in the mapping of agricultural land can achieve ground accuracy of 1,7 cm and height accuracy of 0,6 cm; In addition, when comparing the average accuracy of the 30 plot vertices and the mean lengths from 29 pairs of edges between the newly created map from the UAV image data and the map provided by the Department of Natural Resources and Environment of Phu Tho province, respectively is: 0,181 $\mathrm{m}$ and: 0,051 $\mathrm{m}$.

Copyright @ 2020 Hanoi University of Mining and Geology. All rights reserved.

${ }^{*}$ Corresponding author E - mail: buingocquy@humg.edu.vn DOI: 10.46326/JMES.2020.61(5).05 


\title{
Tạp chí Khoa học Kỹ thuật Mỏ - Địa chất
}

\section{Nghiên cứu khả năng sử dụng thiết bị bay không người lái (UAV) trong thành lập bản đồ địa chính - khu vực đất thổ canh}

\author{
Bùi Ngọc Quý $1{ }^{1}$, Phạm Anh Tuấn ${ }^{2}$, Dương Anh Quân ${ }^{1}$, Phạm Văn Hiệp ${ }^{1}$, Trần \\ Trung Kiên ${ }^{3}$, Hoàng Xuân Tứ ${ }^{4}$, Nguyễn Đại Đồng ${ }^{5}$, Nguyễn Danh Đức ${ }^{1}$, Nguyễn \\ Việt Hưng 6
}

${ }^{1}$ Khoa Trắc địa - Bản đồ và Quản lý đất đai, Trường Đại học Mỏ - Đị chất, Việt Nam

2 Sở Tài nguyên và Môi trường tỉnh Phú Thọ, Việt Nam

${ }^{3}$ Cục Tác chiến, Bộ Tổng Tham mưu, Việt Nam

${ }^{4}$ Công ty Cổ phần Tư vấn Đo đạc Địa chính, Việt Nam

${ }^{5}$ Cục Đo đạc - Bản đồ và Thông tin Địa lý Việt Nam, Việt Nam

${ }^{6}$ Trường Đại học Giao thông Vận tải, Việt Nam

\begin{tabular}{|c|c|}
\hline THÔNG TIN BÀI BÁO & TÓM TẮT \\
\hline $\begin{array}{l}\text { Quá trình: } \\
\text { Nhận bài } 16 / 9 / 2020 \\
\text { Sứa xong } 03 / 10 / 2020 \\
\text { Chấp nhận đăng } 31 / 10 / 2020\end{array}$ & 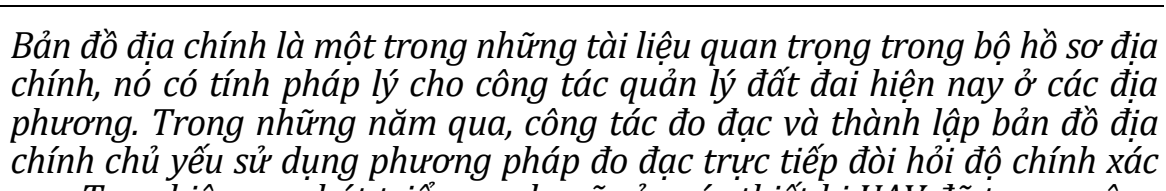 \\
\hline $\begin{array}{l}\text { Tù khóa: } \\
\text { Đất thổ canh, } \\
\text { Địa chính, } \\
\text { UAV. }\end{array}$ & 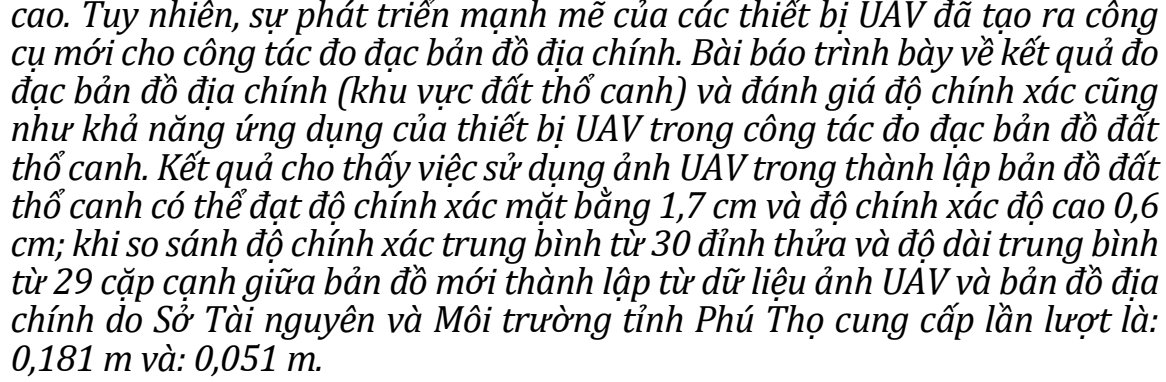 \\
\hline
\end{tabular}

C 2020 Trường Đại học Mỏ - Địa chất. Tất cả các quyền được bảo đảm.

\section{Mở đầu}

Hiện nay, với sự phát triển mạnh mẽ của công nghệ, những thiết bị bay không người lái (UAV) đã

\section{*Tác giả liên hệ}

E- mail: buingocquy@humg. edu.vn DOI: 10.46326/JMES.2020.61(5).05 và đang phát triển một cách nhanh chóng trên nhiều lĩnh vực khác nhau như đo đạc bản đồ, tìm kiếm cứu nạn, cứu hộ, nông nghiệp, quân sự,... Trong lĩnh vực đo đạc và bản đồ, các thiết bị UAV được sử dụng để bay chụp bề mặt địa hình và thành lập các loại bản đồ như: địa hình, địa chính (Kenneth và Tess, 2013; Turner và nnk., 2012; Sebastian và Jochen, 2014; Phạm Ngọc Lãng, 2015). 
Với vai trò là tài liệu quan trọng trong bộ hồ sơ địa chính, bản đồ địa chính có tính pháp lý cao, trợ giúp đắc lực cho công tác quản lý đất đai (Cao Tiến An, 2010). Trước đây, việc thành lập bản đồ chủ yếu dùng phương pháp đo vẽ trực tiếp. Tuy nhiên, phương pháp này mất nhiều thời gian và công sức, đặc biệt là với nhiều dạng địa hình khó có thể triển khai được tốt như địa hình vùng núi cao, đầm lầy. Do đó, việc thành lập bản đồ địa chính bằng UAV đã giúp tiết kiệm được thời gian và chi phí, đặc biệt đã giải quyết được những khó khăn trong việc đo vẽ trực tiếp ở những nơi có địa hình đặc biệt (Bùi Ngọc Quý, Phạm Văn Hiệp, 2017).

Trong những năm qua, đã có nhiều nghiên cứu và ứng dụng UAV trong đo vẽ và thành lập bản đồ (Bùi Tiến Diệu và nnk., 2016; Bùi Ngọc Quý, Phạm Văn Hiệp, 2018; Nguyễn Viết Nghĩa, 2020; Le Van Canh và nnk., 2020), ứng dụng ảnh UAV trong nghiên cứu địa hình và thành lập bản đồ các khu vực mỏ lộ thiên (Nguyen Quoc Long, 2019; Bui, Xuan Nam và nnk., 2019). Tuy nhiên, chưa có nghiên cứu nào đánh giá được tính ưu việt cũng như so sánh được độ chính xác của bản đồ đất thổ canh thành lập từ dữ liệu ảnh UAV với các bản đồ địa chính chính quy đã có. Vì vậy, việc nghiên cứu đánh giá khả năng sử dụng thiết bị bay không người lái (UAV) thành lập bản đồ địa chính khu vực đất thổ canh có ý nghĩa khoa học và thực tiễn cao.

\section{Khu vực nghiên cứu}

Khu vực nghiên cứu thực nghiệm (Hình 1) thuộc xã Sơn Tình, huyện Cẩm Khê, tỉnh Phú Thọ, địa hình nơi đây có độ dốc thấp, cơ cấu các loại đất mang tính đa dạng, nằm xen lẫn nhau. Diện tích đất thổ canh ở xã Sơn Tình là khoảng 190 ha còn lại là đất thổ cư tập trung chủ yếu ở các xóm nhỏ xen lẫn là đất thổ canh và đất đồi thấp.

\section{Thành lập bản đồ đất thổ canh từ dữ liệu ảnh UAV}

\subsection{Quy trình thành lập bản đồ địa chính bằng công nghệ UAV}

Quy trình công nghệ thành lập bản đồ đất thổ canh khu vực thực nghiệm được tiến hành theo quy trình (Hình 2).

\subsection{Thiết kế tuyến bay}

Công tác thiết kế bay chụp cơ bản bao gồm tính toán độ cao bay của UAV, xác định độ phủ dọc và độ phủ ngang của ảnh, thiết kế và tính toán số đường bay, ước tính tổng số ảnh cần chụp và tổng dung lượng ảnh, tính tốc độ chụp và tổng thời gian bay.

Các tham số cho công tác thiết kế bay chụp được xác định tùy thuộc vào diện tích bay chụp và độ chính xác của sản phẩm bản đồ. Sau đó, chúng được nhập vào phần mềm quản lý và thực hiện bay chụp như Pix4Dcapture, Mission Planner, Dji Ground Control Station.

Dựa vào công thức (Sona và nnk., 2014):

$$
H_{B C}=\frac{L_{i m} \cdot G S D \cdot f_{k}}{L_{S S} \cdot 100}, \mathrm{~m}
$$

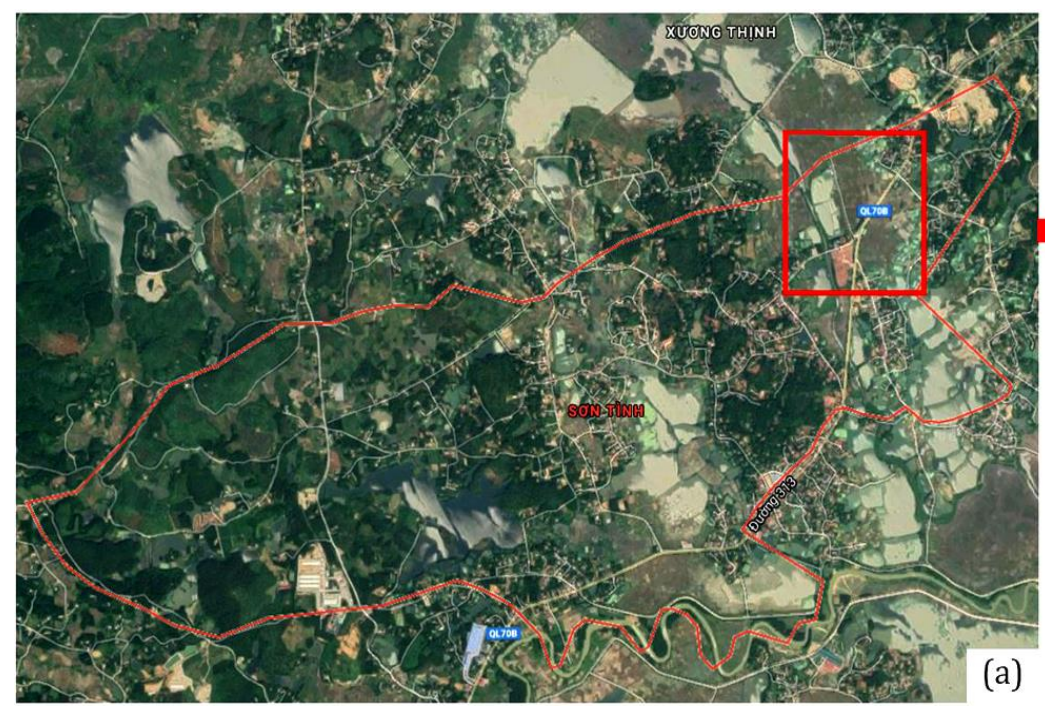

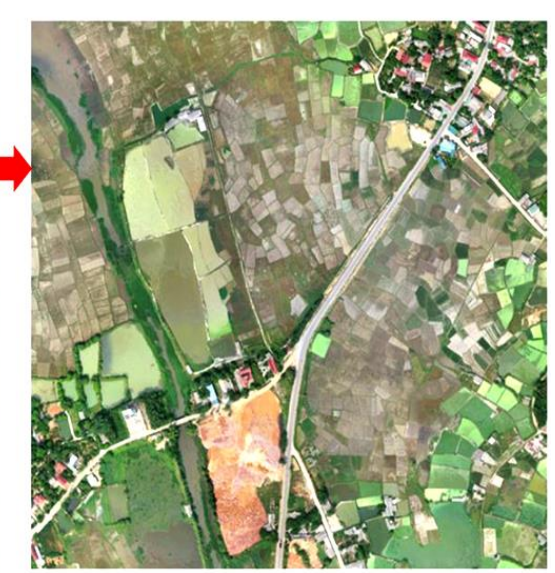

(b)

Hình 1. Khu vực nghiên cúu, phạm vi thực nghiệm. (a) hình vuông màu đỏ, (b) ảnh chụp phạm vi đo vẽ. 


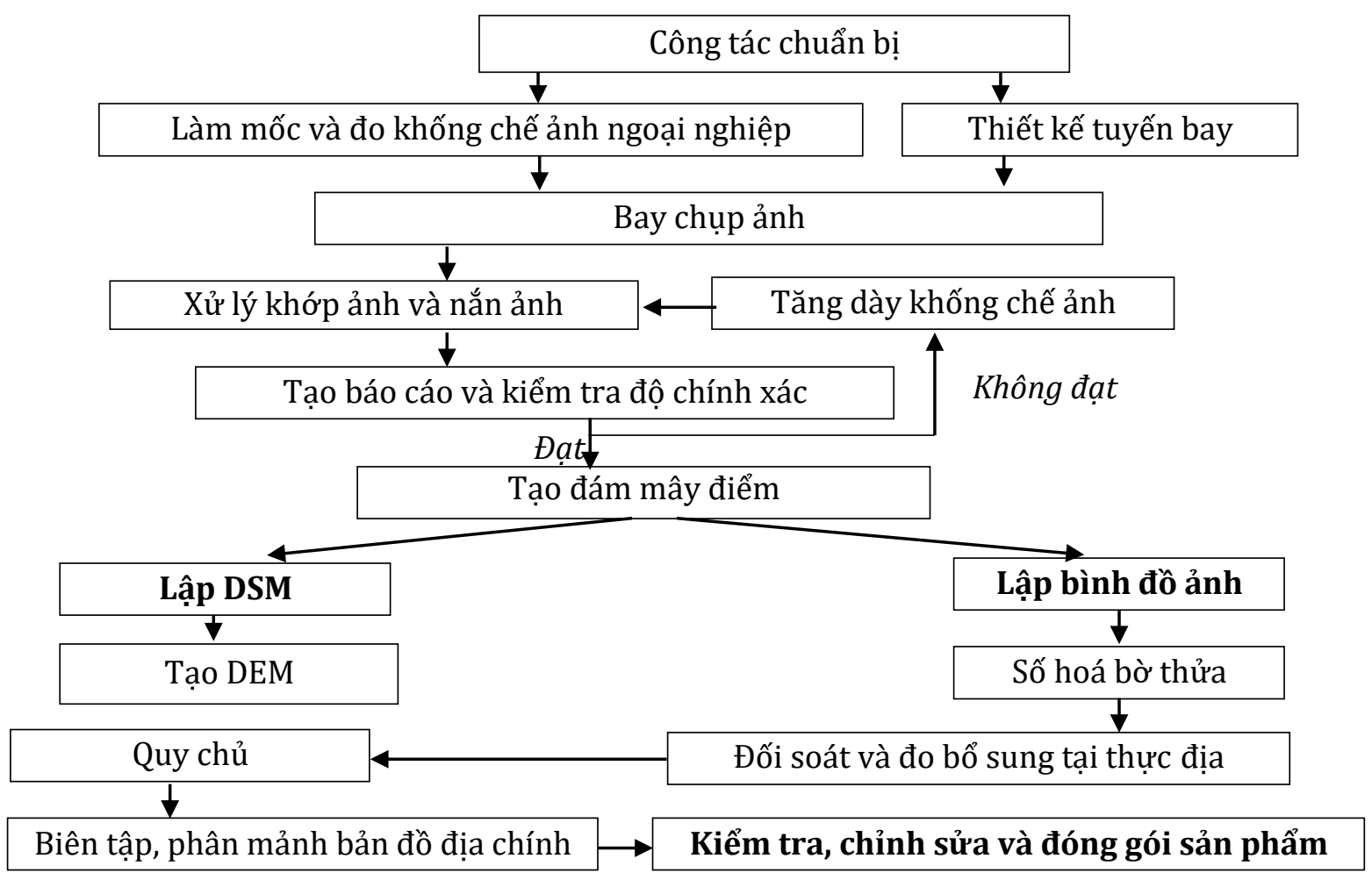

Hình 2. Sơ đồ quy trình thành lập bản đồ địa chính từ tư liệu ảnh chụp UAV.

Trong đó: $H_{B C}$ - độ cao bay chụp của UAV, m; $L_{i m}$ (image Length) - độ dài của ảnh chụp, pixcel; GSD (Ground Sample Distance) - độ phân giải mặt đất, $\mathrm{cm}$; $f k$ - tiêu cự của máy chụp ảnh, đơn vị mm; $L_{S S}$ (Sensor Length) - chiều dài của cảm biến thu nhận ảnh của máy ảnh, $\mathrm{mm}$.

Công thức (2).

$n=$ WPr.ma. WSS.(100-q\%) .100

Trong đó: $n$ - số dải bay; $W P r$ - độ rộng khu vực bay chụp, m; $m a$ - mẫu số tỷ lệ ảnh; WSS - chiều rộng của Sensor, m; q\% - độ phủ ngang.

\subsection{Bố trí và đo đạc điểm khống chế ảnh}

Để thực hiện đo lưới khống chế ảnh trong quá trình bay chụp ảnh UAV sẽ đồng thời tiến hành đo lưới khống chế ảnh để phục vụ cho quá trình xử lý ảnh sau này. Trong bài báo này nhóm nghiên cứu đã sử dụng phương pháp định vị vệ tinh GNSS/RTK để đo các điểm khống chế ảnh. Số lượng điểm khống chế ảnh gồm 2 điểm gốc tọa độ nhà nước VN2000 (điểm Đia chính cơ sở 091463 và 091486) và 6 điểm khống chế ảnh (Hình 3), trong đó 5 điểm (KCA1, KCA2, KCA3, KCA5, KCA6) sẽ được sử dụng cho công tác tính toán, điểm KCA4 được dùng để kiểm tra. Do phần mềm chụp

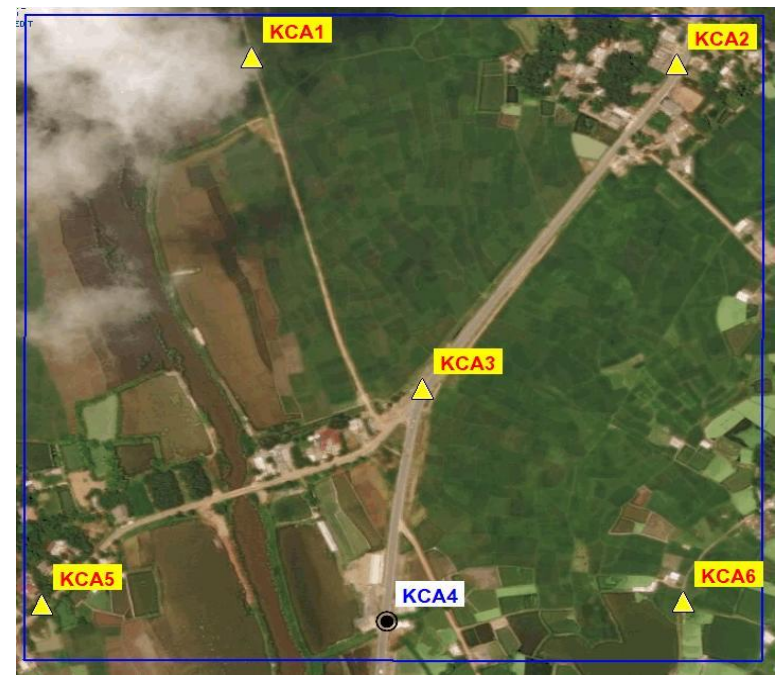

Hình 3. Sơ đồ thiết kế khống chế ảnh.

ảnh UAV được thiết kế trên nền bản đồ Google Earth (hệ tọa độ WGS84) nên dữ liệu ảnh sau khi thu nhận được cần phải chuyển về hệ tọa độ VN2000 để thành lập bản đồ.

Do địa hình của khu vực thực nghiệm có chênh cao không lớn (chênh cao giữa điểm cao nhất và thấp nhất <10 m) vì vậy có thể dễ dàng bố trí trải đều các điểm khống chế trong phạm vi thực nghiệm. 


\subsection{Bay chụp ảnh UAV}

\subsubsection{Thiết bị thực nghiệm}

Trước khi tiến hành thực nghiệm nhóm nghiên cứu đã tiến hành khảo sát 1 số loại thiết bị UAV trong thực tế hiện nay và thấy rằng có nhiều chủng loại khác nhau, tuy nhiên trong các đơn vị đo đạc bản đồ hiện nay các thiết bị UAV được chia làm 2 loại chính là lên thẳng và dùng bệ phóng. Trong phạm vi bài báo này nhóm nghiên cứu đã tiến hành sử dụng thiết bị DJI Phantom 4 pro, đây là loại máy bay lên thẳng để tiến hành bay chụp ảnh khu vực thực nghiệm (Bảng 1, 2).

Bảng 1. Thông số kỹ thuật cơ bản của DJI Phantom 4 pro (https://www.dji.com).

\begin{tabular}{|l|l|}
\hline \multicolumn{1}{|c|}{ Trọng lượng máy } & \multicolumn{1}{c|}{$1380 \mathrm{~g}$} \\
\hline Hệ thống định vị GPS & GPS/GLONASS \\
\hline Tốc độ cất/ hạ cánh tối đa & 4 / 6 (m/giây) \\
\hline Tốc độ bay & $20 \mathrm{~m} /$ giây \\
\hline $\begin{array}{l}\text { Độ cao bay so với mực nước } \\
\text { biển }\end{array}$ & $6000 \mathrm{~m}$ \\
\hline $\begin{array}{l}\text { Tốc độ gió tối đa để thiết bị } \\
\text { hoạt động }\end{array}$ & $10 \mathrm{~m} /$ giây \\
\hline Thời gian bay tối đa & Khoảng 28 phút \\
\hline
\end{tabular}

Bảng 2. Thông số kỹ thuật cơ bản của máy ảnh (https://www.dji.com).

\begin{tabular}{|l|l|}
\hline \multicolumn{1}{|c|}{ Cảm biến } & $\begin{array}{l}1 / 2,3^{\prime \prime} \text { CMOS; } \\
\text { Effective pixels: 20 Mp }\end{array}$ \\
\hline Ống kính & $\begin{array}{l}\text { FOV } 94^{\circ} 20 \mathrm{~mm}(35 \mathrm{~mm} \text { format } \\
\text { equivalent) f/2.8 focus at } \infty\end{array}$ \\
\hline Độ nhạy sáng & $\begin{array}{l}100 \div 3200 \text { (video) / 100 } 1600 \\
\text { (photo) }\end{array}$ \\
\hline $\begin{array}{l}\text { Tốc độ màn trập } \\
\text { điện tử }\end{array}$ & $8 \div 1 / 8000 \mathrm{~s}$ \\
\hline Kích thước ảnh & $5472 \times 3648$ \\
\hline $\begin{array}{l}\text { Chế độ chụp } \\
\text { ảnh tĩnh }\end{array}$ & $\begin{array}{l}\text { Chụp một lần liên tục: } 3 / 5 / 7 \\
\text { hình. Phơi sáng tự động: } 3 / 5\end{array}$ \\
\hline Định dạng ảnh & JPEG, DNG (RAW) \\
\hline
\end{tabular}

\subsubsection{Công tác chụp ảnh}

Quá trình thiết kế bay chụp được thực hiện trên phần mềm Map Pilot, đây là phần mềm chuyên dụng được xây dựng để thiết kế tuyến bay tích hợp với nền bản đồ Google map. Khu vực thực nghiệm được thiết kế bay gồm 13 dải bay ở độ cao bay chụp 170 m so với vị trí cất cánh và có độ phủ trùm ảnh $80 \div 75 \%$ (Hình 4).

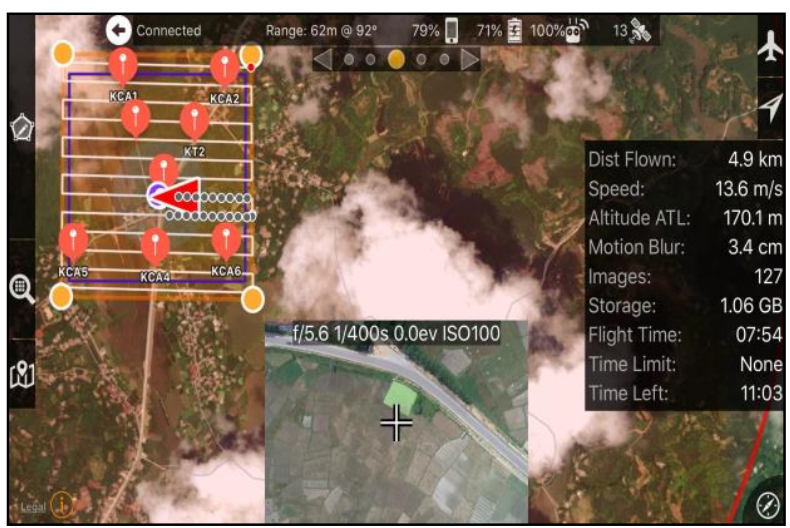

Hình 4. Sơ đồ tuyến bay được thiết kế trên phần mềm Map Pilot.

\subsection{Xử lý dũ liệu ảnh chụp phục vụ công tác thành lập bản đồ đất thố canh}

Nhóm nghiên cứu đã sử dụng phần mềm Pix4Dmapper để thực hiện việc xử lý ảnh sau khi bay chụp. Tiến hành nhập và khai báo các điểm khống chế mặt đất, xác định các thông số cần thiết cho các loai dữ liệu đầu ra và tiến hành quá trình khớp ảnh và tạo đám mây điểm (Point Cloud) cho khu vực thực nghiệm.

Từ dữ liệu Point cloud tiến hành tạo mô hình số bề mặt (DSM), sau khi có kết quả DSM sẽ dựa vào chỉ số màu của các điểm point cloud và độ dốc của địa hình để tiến hành lọc lấy các điểm mặt đất và sử dụng phương pháp nội suy liền kề (neighbor) để loại bỏ độ cao địa vật. Kết quả xử lý sẽ thu được dữ liệu độ cao của toàn bộ các điểm mặt đất. Từ dữ liệu này tiến hành nội suy ra mô hình DEM (Bùi Ngọc Quý, Phạm Văn Hiệp, 2017; 2018).

Kết quả quá trình xử lý ảnh cho thấy độ chính xác của các điểm khống chế mặt đất và các điểm kiểm tra (Bảng 3) là khá cao. Sai số vị trí mặt bằng đạt $1,7 \mathrm{~cm}$ và sai số độ cao đạt $6 \mathrm{~cm}$ so với quy định của quy phạm thành lập bản đồ địa chính (Bảng 4), cho thấy kết quả xử lý hoàn toàn đảm bảo độ chính xác cho tỷ lệ 1:2000 của khu vực thực nghiệm.

Kết quả của quá trình xử lý này thu được sản phẩm gồm đám mây điểm (Pointcloud), bình đồ ảnh và mô hình số bề mặt (DSM). Tuy nhiên, trong phạm vi của bài báo chỉ tập trung vào việc xác định tọa độ góc thửa, độ chính xác mặt bằng của công tác xử lý ảnh phục vụ thành lập bản đồ đất thổ canh nên chỉ quan tâm đến sản phẩm là bình đồ ảnh (Hình 5). 


\subsection{Kết quả xây dưng bản đồ đất thổ canh cho khu vực thực nghiệm}

Sau quá trình xử lý và tạo bình đồ ảnh, tiến hành số hóa độc lập trên cơ sở của phần mềm thành lập bản đồ MicroStation $\mathrm{SE}$ và Autocad 2007 để thành lập bản đồ đất thổ canh cho khu vực thực nghiệm. Kết quả nhận được bản đồ đất

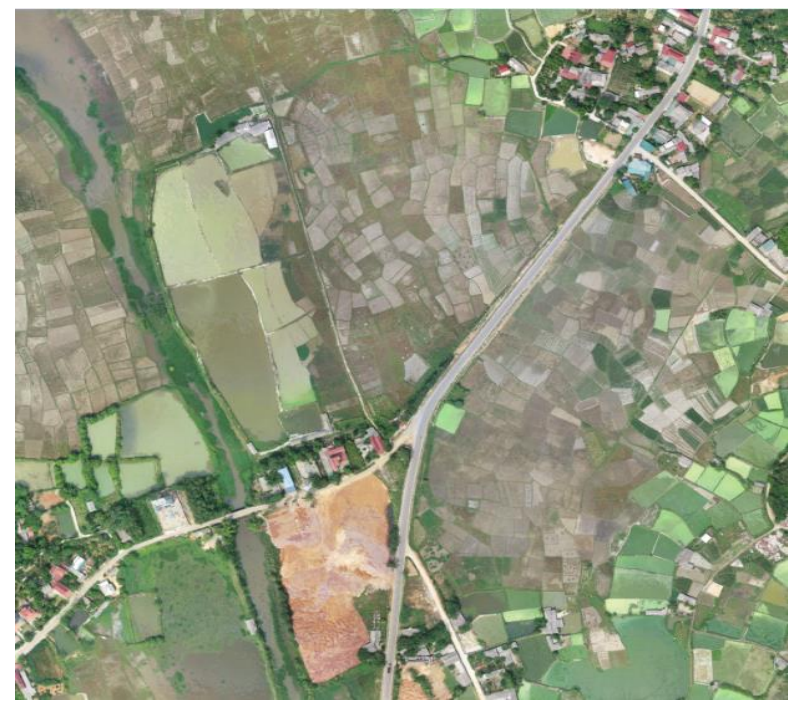

Hình 5. Bình đồ ảnh của khu vực thực nghiệm. thổ canh cho mảnh bản đồ số 9 xã Sơn Tình, huyện Cẩm Khê, tỉnh Phú Thọ.

4. Đánh giá khả năng sử dụng thiết bị bay không người lái trong thành lập bản đồ địa chính khu vực đất thổ canh

\section{1. Độ chính xác bản đồ địa chính}

Độ chính xác của bản đồ địa chính là mối quan tâm hàng đầu khi đưa ra một sản phẩm mới. Vì vậy, để đảm bảo độ chính xác của bản đồ cần thành lập thì phải đạt được những chỉ tiêu kỹ thuật như theo Thông tư số 25/2014/TT-BTNMT ngày 19/05/2014 của Bộ Tài nguyên và Môi trường (Bảng 4).

\section{2. Đánh giá khả năng ứng dụng công nghệ bay chụp ảnh bằng máy bay không người lái trong đo vẽ bản đồ địa chính}

Sau quá trình thực nghiệm và tiến hành so sánh, đánh giá sai số của bản đồ thực nghiệm cho vùng đất thổ canh của xã Sơn Tình, huyện Cẩm Khê, tỉnh Phú Thọ từ dữ liệu ảnh máy bay không người lái Phantom 4 và bản đồ địa chính số do

Bảng 3. Sai số của các điểm khống chế ảnh mặt đất và điểm kiểm tra.

\begin{tabular}{|c|c|c|c|c|}
\hline TT & Tên điểm & Sai số theo trục X(m) & Sai số theo trục Y(m) & Sai số độ cao (m) \\
\hline \multicolumn{5}{|c|}{ Các điểm tham gia tính toán } \\
\hline 1 & GCP.KCA1 & $-0,022$ & $-0,014$ & $-0,011$ \\
\hline 2 & GCP.KCA2 & 0,015 & $-0,015$ & 0,004 \\
\hline 3 & GCP.KCA3 & $-0,024$ & 0,000 & $-0,004$ \\
\hline 4 & GCP.KCA5 & $-0,007$ & 0,010 & 0,001 \\
\hline 5 & GCP.KCA6 & $-0,012$ & 0,017 & 0,004 \\
\hline \multicolumn{5}{|c|}{ Sai số điểm kiểm tra } \\
\hline 1 & KCA4 & 0,003 & 0,006 & 0,072 \\
\hline \multicolumn{2}{|c|}{ Sai số trung phương } & 0,017 & 0,013 & 0,006 \\
\hline
\end{tabular}

Bảng 4. Độ chính xác yêu cầu của bản đồ địa chính.

\begin{tabular}{|c|l|l|}
\hline TT & \multicolumn{1}{|c|}{ Các yếu tố yêu cầu về độ chính xác } & \multicolumn{1}{|c|}{ Chỉ tiêu kỹ thuật } \\
\hline 1 & $\begin{array}{l}\text { Sai số trung phương vị trí mặt phẳng của điểm khống chế đo vẽ, Điểm } \\
\text { khống chế ảnh, điểm trạm đo so với điểm khởi tính sau bình sai, tính theo } \\
\text { tỷ lệ bản đồ cần thành lập. }\end{array}$ & $\leq 0,1 \mathrm{~mm}$ \\
\hline 2 & $\begin{array}{l}\text { Sai số vị trí của điểm bất kỳ trên ranh giới thửa đất biểu thị trên bản đồ } \\
\text { địa chính dạng số so với vị trí của các điểm khống chế đo vẽ gần nhất. }\end{array}$ & $\begin{array}{l}\leq 7 \mathrm{~cm}(1: 500) \\
\leq 15 \mathrm{~cm}(1: 1000) \\
\leq 30 \mathrm{~cm}(1: 2000)\end{array}$ \\
\hline 3 & $\begin{array}{l}\text { Sai số tương hỗ vị trí điểm của } 2 \text { điểm bất kỳ trên ranh giới thửa đất biểu } \\
\text { thị trên bản đồ địa chính dạng số so với khoảng cách trên thực địa được } \\
\text { đo trực tiếp hoặc đo gián tiếp từ cùng một trạm máy, theo tỷ lện bản đồ. }\end{array}$ & $\begin{array}{l}\leq 0,3 \mathrm{~mm} \text { mm, với đất nông } \\
\text { nghiệp }(1: 1000 ; 1: 2000)\end{array}$ \\
\hline
\end{tabular}


Sở Tài nguyên và Môi trường tỉnh Phú Thọ cung cấp, có thể thấy được phương pháp sử dụng UAV hoàn toàn có khả năng thành lập được bản đồ đất thổ canh với độ chính xác đảm bảo đáp ứng theo đúng quy phạm thành lập bản đồ địa chính (phần đất thổ canh) đối với tỷ lệ bản đồ 1:2.000.

\subsection{1. Đánh giá các kết quả xử lý dũ̃ liệu ảnh UAV cho công tác thành lập bản đồ đất thổ canh của khu vực thực nghiệm}

Việc nghiên cứu, thử nghiệm và đánh giá một phương pháp mới đi đến kết quả cuối cùng phụ thuộc phần lớn vào sản phẩm tạo ra. Trong nghiên cứu này sản phẩm cuối cùng là bản đồ đất thổ canh được thành lập từ ảnh chụp bằng hệ thống DJI Phantom 4 Pro.

Để có đánh giá khách quan và chính xác hơn thì ta cần sử dụng phương pháp đánh giá sai số trung phương theo tọa độ đỉnh thửa và theo chiều dài cạnh giữa hai loại bản đồ. Số liệu dùng để đánh giá và so sánh được nhóm nghiên cứu sử dụng là số liệu đã đo vẽ chi tiết bằng máy toàn đạc điện tử cho khu vực này do Sở Tài nguyên và Môi trường tỉnh Phú Thọ cung cấp.

\section{Đánh giá độ chính xác xử lý dũ liệu ảnh UAV}

Việc đánh giá độ chính xác kết quả đo vẽ ảnh chính là việc đánh giá độ chính xác của các điểm khống chế ảnh. Các điểm khống chế ảnh cần đảm bảo được độ chính xác cao hơn 1 cấp so với độ chính xác của các điểm địa vật. Trong công tác đo vẽảnh thì sai số cho phép của điểm khống chế tăng dày chỉ được phép bằng 2 lần sai số trung bình với số lần xuất hiện tối đa là $5 \%$ đối với điểm độ cao của điểm tăng dày, vùng khó khăn cho phép số lần xuất hiện tối đa là $10 \%$. Sau quá trình tăng dày điểm khống chế ảnh, tiến hành kiểm tra độ chính xác lại thêm lần nữa để đảm bảo tính chính xác của kết quả thực nghiệm.

Để đánh giá độ chính xác của bản đồ, có thể sử dụng công thức tính sai số trung phương RMSE sau (Bùi Tiến Diệu, 2016):

$R S M E=$ với: $n$ là tổng số điểm kiểm tra; $e=V m a p-$ Vtest

Trong đó: Vmap - tọa độ x, hoặc tọa độ $y$, hoặc độ cao $z$ trên bản đồ; Vtest - tọa độ $x$, hoặc tọa độ $y$, hoặc độ cao $z$ tại các điểm khống chế;

Quá trình xử lý ảnh nhóm nghiên cứu đã thực hiện xử lý dữ liệu với 5 điểm khống chế ảnh và sử dụng 1 điểm còn lại để kiểm tra kết quả xử lý độ chính xác mặt bằng và độ cao. Từ kết quả thực nghiệm kiểm tra độ chính xác mặt bằng và độ cao (Bảng 3 ) có thể thấy rằng độ chính xác mặt bằng có thể đạt được là $1,7 \mathrm{~cm}$ và độ chính xác độ cao có thể đạt được là $0,6 \mathrm{~cm}$. Tuy nhiên, trong phạm vi bài báo này không chú trọng nhiều đến độ cao. Như vậy, có thể nói rằng việc ứng dụng dữ liệu UAV trong thành lập các bản đồ đất thổ canh là hoàn toàn khả thi và đảm bảo được độ chính xác.

Đánh giá độ chính xác của bản đồ đất thổ canh được thành lập bằng dũ liệu UAV so với bản đồ địa chính số của Sở Tài nguyên và Môi trường tỉnh Phú Thọ.

Trên cơ sở dữ liệu bản đồ thành lập bằng ảnh UAV nhóm nghiên cứu chồng xếp lên bản đồ được thành lập bằng phương pháp toàn đạc điện tử do Sở TN\&MT tỉnh Phú Thọ cung cấp cho thấy, các thửa màu xanh là nền của bản đồ địa chính số do Sở TN\&MT cung cấp và các thửa màu đỏ là bản đồ đất thổ canh được thành lập bằng dữ liệu UAV (Hình 6). Từ Hình 6 có thể thấy sự trùng khớp giữa các đỉnh thửa trên bản đồ địa chính của Sở TN\&MT và ranh giới của bản đồ đất thổ canh được thành lập bằng dữ liệu UAV là rất cao, với góc nhìn và tỷ lệ này khó có thể phân biệt sự sai khác giữa hai đường ranh giới này. Tuy nhiên, để có thể đánh giá chính xác được kết quả nghiên cứu, nhóm nghiên cứu đã tiến hành so sánh tọa độ 30 đỉnh thửa của bản đồ số địa chính của Sở TN\&MT và bản đồ đất thổ canh được thành lập bằng dữ liệu UAV và cho thấy kết quả như trong Bảng 5,6 .

- Sai số trung phương trung bình vị trí theo tọa độ đỉnh thửa được tính theo công thức (3):

$$
m_{x}=\sqrt{\frac{\Sigma \Delta^{2} x_{i}}{n}} ; m_{y}=\sqrt{\frac{\Sigma \Delta^{2} y_{i}}{n}}
$$

Trong đó: $i$ - số thứ tự đỉnh thửa; $n$ - số đỉnh thửa.

- Sai số theo chiều dài cạnh được tính theo công thức (4):

$$
m=\sqrt{\frac{\Sigma \Delta^{2} d_{i}}{n-1}}
$$

Trong đó: $i$ - số thứ tự cạnh; $n$ - số cạnh.

Sai số tọa độ từ 30 đỉnh thửa là $0,181 \mathrm{~m}$. Tương tự cũng tính được sai số từ độ dài 29 cặp cạnh giữa hai bản đồ là $0,051 \mathrm{~m}$. 


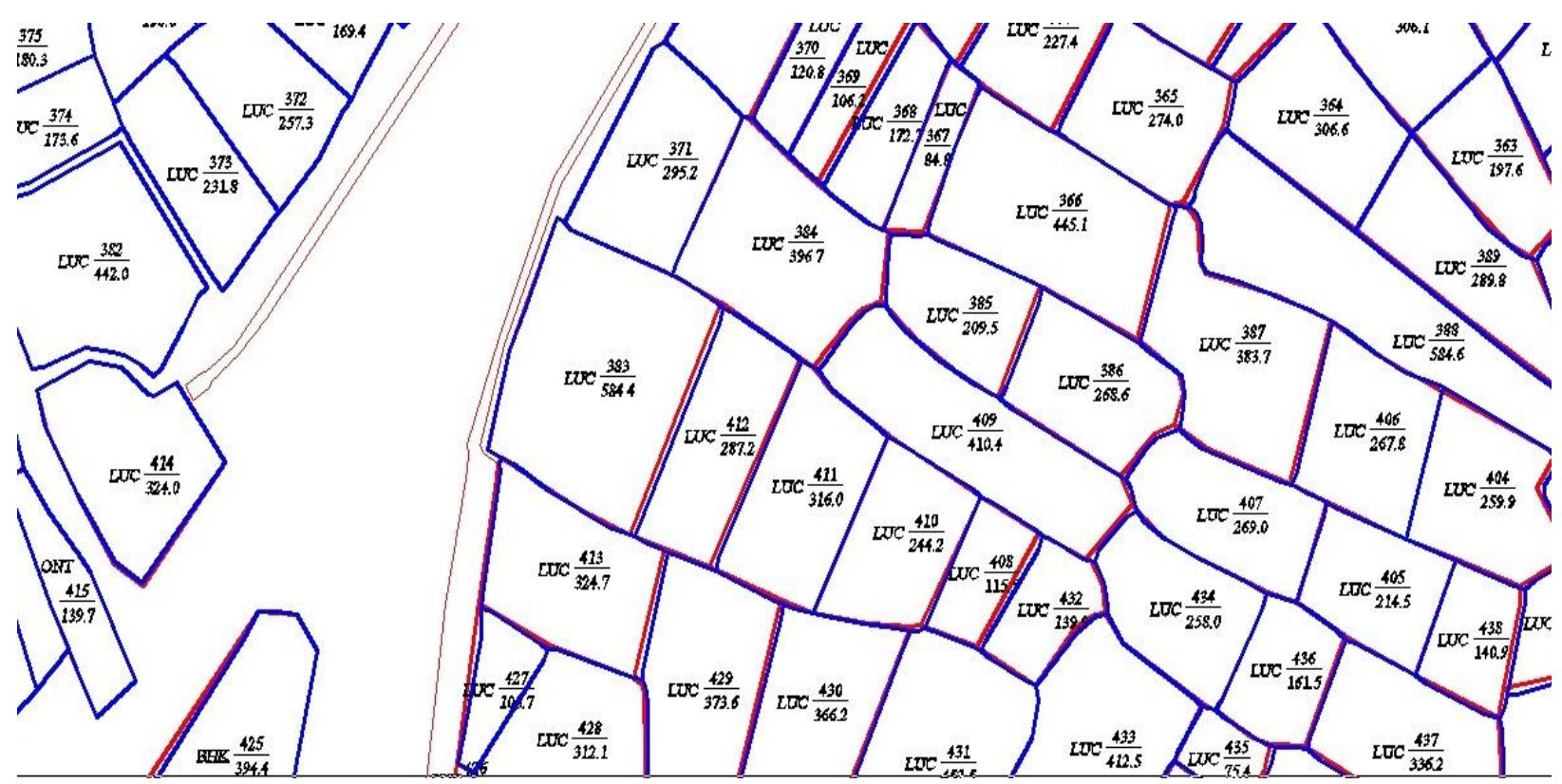

Hình 6. Tương quan giũa các đỉnh thửa đo vẽ chi tiết và số hóa trên nền ảnh.

Bảng 5. Bảng sai số tọa độ của các đỉnh thứa.

\begin{tabular}{|c|c|c|c|c|c|c|}
\hline \multirow{2}{*}{$\begin{array}{c}\text { TT } \\
\text { điểm }\end{array}$} & $\begin{array}{c}\text { Bản đồ địa chính số do Sở Tài nguyên } \\
\text { và Môi trường cung cấp }\end{array}$ & \multicolumn{2}{|c|}{$\begin{array}{c}\text { Bản đồ đất thổ canh khu vực thực } \\
\text { nghiệm được thành lẩp từ UAV }\end{array}$} & \multirow{2}{*}{$\Delta \mathrm{x}$} & \multirow{2}{*}{$\Delta \mathrm{y}$} \\
\cline { 2 - 6 } & $\mathrm{x}(\mathrm{m})$ & $\mathrm{y}(\mathrm{m})$ & $\mathrm{x}(\mathrm{m})$ & $\mathrm{y})$ & \\
\hline 1 & 2368207,740 & 536819,410 & 2368207,734 & 536819,424 & 0,006 & 0,014 \\
\hline 2 & 2368204,470 & 536823,860 & 2368204,465 & 536823,862 & 0,005 & 0,002 \\
\hline 3 & 2368200,370 & 536829,640 & 2368200,366 & 536829,642 & 0,004 & 0,002 \\
\hline 4 & 2368199,770 & 536831,310 & 2368199,765 & 536831,318 & 0,005 & 0,008 \\
\hline 5 & 2368199,280 & 536832,270 & 2368199,278 & 536832,279 & 0,002 & 0,009 \\
\hline 6 & 2368199,030 & 536835,910 & 2368199,028 & 536835,911 & 0,002 & 0,001 \\
\hline 7 & 2368198,730 & 536837,880 & 2368198,728 & 536837,882 & 0,002 & 0,002 \\
\hline 8 & 2368193,540 & 536851,390 & 2368193,520 & 536851,392 & 0,020 & 0,002 \\
\hline 9 & 2368187,60 & 536863,630 & 2368187,596 & 536863,636 & 0,004 & 0,006 \\
\hline 10 & 2368184,030 & 536868,950 & 2368184,029 & 536868,957 & 0,001 & 0,007 \\
\hline 11 & 2368182,290 & 536869,320 & 2368182,283 & 536869,321 & 0,007 & 0,001 \\
\hline 12 & 2368178,460 & 2368178,50 & 2368178,443 & 2368178,466 & 0,017 & 0,006 \\
\hline 13 & 2368176,390 & 536871,520 & 2368176,387 & 536871,537 & 0,003 & 0,017 \\
\hline 14 & 2368172,810 & 536881,320 & 2368172,792 & 536881,325 & 0,018 & 0,005 \\
\hline 15 & 2368170,520 & 536887,150 & 2368170,515 & 536887,154 & 0,005 & 0,004 \\
\hline 16 & 2368166,750 & 536897,120 & 2368166,779 & 536897,190 & 0,029 & 0,003 \\
\hline 17 & 2368164,440 & 536903,350 & 2368164,53 & 536903,430 & 0,090 & 0,004 \\
\hline 18 & 2368161,750 & 536911,450 & 2368161,785 & 536911,540 & 0,035 & 0,003 \\
\hline 19 & 2368165,120 & 536917,720 & 2368165,2 & 536917,810 & 0,080 & 0,090 \\
\hline 20 & 2368171,710 & 536925,360 & 2368171,79 & 536925,410 & 0,080 & 0,050 \\
\hline 21 & 2368171,360 & 536930,610 & 2368171,42 & 536930,690 & 0,060 & 0,080 \\
\hline 22 & 2368170,370 & 536931,230 & 2368170,42 & 536931,320 & 0,050 & 0,090 \\
\hline 23 & 2368149,250 & 536939,020 & 2368149,36 & 536939,100 & 0,110 & 0,080 \\
\hline 24 & 2368148,880 & 536939,490 & 2368148,884 & 536939,493 & 0,004 & 0,003 \\
\hline 25 & 2368137,870 & 536928,050 & 2368137,872 & 536928,054 & 0,002 & 0,004 \\
\hline 26 & 2368130,450 & 536930,90 & 2368130,456 & 536930,907 & 0,006 & 0,007 \\
\hline 27 & 2368130,010 & 536931,530 & 2368130,016 & 536931,532 & 0,006 & 0,002 \\
\hline
\end{tabular}




\begin{tabular}{|l|l|l|l|l|l|l|}
\hline 28 & 2368124,780 & 536928,540 & 2368124,784 & 536928,545 & 0,004 & 0,005 \\
\hline 29 & 2368123,740 & 536927,810 & 2368123,743 & 536927,815 & 0,003 & 0,005 \\
\hline 30 & 2368112,740 & 536919,690 & 2368112,744 & 536919,692 & 0,004 & 0,002 \\
\hline \multicolumn{7}{|c|}{ Sai số vị trí điểm tổng hợp: 0,181 (m) } \\
\hline
\end{tabular}

Bảng 6. Bảng sai số các cạnh thửa.

\begin{tabular}{|c|c|c|c|c|c|c|c|c|c|}
\hline TT & Cạnh & $\begin{array}{c}\text { Số liệu trên } \\
\text { bản đồ địa } \\
\text { chính }(\mathrm{m})\end{array}$ & $\begin{array}{c}\text { Số liệu trên bản } \\
\text { đồ đất thổ canh } \\
(\mathrm{m})\end{array}$ & $\begin{array}{c}\text { Chênh } \\
\text { lệch }(\mathrm{m})\end{array}$ & $\mathrm{TT}$ & Cạnh & $\begin{array}{c}\text { Số liệu trên } \\
\text { bản đồ địa } \\
\text { chính }(\mathrm{m})\end{array}$ & $\begin{array}{c}\text { Số liệu trên } \\
\text { bản đồ đất thổ } \\
\text { canh }(\mathrm{m})\end{array}$ & $\begin{array}{c}\text { Chênh } \\
\text { lệch }(\mathrm{m})\end{array}$ \\
\hline 1 & $1-2$ & 5,52 & 5,51 & 0,01 & 16 & $16-17$ & 6,64 & 6,63 & 0,01 \\
\hline 2 & $2-3$ & 7,09 & 7,09 & 0 & 17 & $17-18$ & 8,53 & 8,56 & $-0,03$ \\
\hline 3 & $3-4$ & 1,77 & 1,78 & $-0,01$ & 18 & $18-19$ & 7,12 & 7,14 & $-0,02$ \\
\hline 4 & $4-5$ & 1,08 & 1,08 & 0 & 19 & $19-20$ & 10,09 & 10,06 & 0,03 \\
\hline 5 & $5-6$ & 3,65 & 3,64 & 0,01 & 20 & $20-21$ & 5,26 & 5,29 & $-0,03$ \\
\hline 6 & $6-7$ & 1,99 & 1,99 & 0 & 21 & $21-22$ & 1,17 & 1,18 & $-0,01$ \\
\hline 7 & $7-8$ & 14,47 & 14,48 & $-0,01$ & 22 & $22-23$ & 22,51 & 22,45 & 0,06 \\
\hline 8 & $8-9$ & 13,61 & 13,60 & 0,01 & 23 & $23-24$ & 0,60 & 0,62 & $-0,02$ \\
\hline 9 & $9-10$ & 6,41 & 6,41 & 0 & 24 & $24-25$ & 15,88 & 15,88 & 0 \\
\hline 10 & $10-11$ & 1,78 & 1,78 & 0 & 25 & $25-26$ & 7,95 & 7,95 & 0 \\
\hline 11 & $11-12$ & 3,89 & 4,00 & $-0,11$ & 26 & $26-27$ & 0,77 & 0,76 & 0,01 \\
\hline 12 & $12-13$ & 3,56 & 3,57 & $-0,01$ & 27 & $27-28$ & 6,02 & 6,02 & 0 \\
\hline 13 & $13-14$ & 10,43 & 10,43 & 0 & 28 & $28-29$ & 1,27 & 1,27 & 0 \\
\hline 14 & $14-15$ & 6,26 & 6,26 & 0 & 29 & $29-30$ & 13,67 & 13,67 & 0 \\
\hline 15 & $15-16$ & 10,65 & 10,64 & 0,01 & & & & & \\
\hline
\end{tabular}

Từ các kết quả tính được ở trên cho thấy, sai số được so sánh với bản đồ địa chính số do Sở TN\&MT tỉnh Phú Thọ cung cấp cũng không khác nhiều khi đối chiếu với bản đồ số hóa trên nền bình đồ ảnh bay chụp. Đồng thời kết quả so sánh sai số xử lý ảnh với quy phạm là hoàn toàn nằm trong hạn sai cho phép. Như vậy, có thể thấy rằng bản đồ địa chính (khu vực đất thổ canh) được thành lập từ ảnh máy bay không người lái hoàn toàn đảm bảo được độ chính xác theo yêu cầu của quy định hiện hành.

Kiểm tra độ chính xác của dũ liệu ảnh UAV sau xử lý với bản đồ địa chính số của Sở Tài nguyên và Môi trường tỉnh Phú Tho

Từ Hình 7 có thể thấy sự trùng khớp giữa các thửa trên bản đồ địa chính của Sở TN\&MT và dữ liệu ảnh UAV sau xử lý cho thấy sự trùng khớp giữa các ranh thửa so với nền ảnh là rất cao. Điều đó cho thấy rằng ảnh bay chụp bằng thiết bị Phantom 4 pro có độ tin cậy cao, phù hợp với việc thành lập bản đồ đất thổ canh. Tuy nhiên, khi so sánh nền ảnh sau khi xử lý (đã đánh giá độ chính xác trong Bảng 4) cho thấy dữ liệu bản đồ địa chính do Sở TN\&MT cấp thì các điểm góc thửa đều

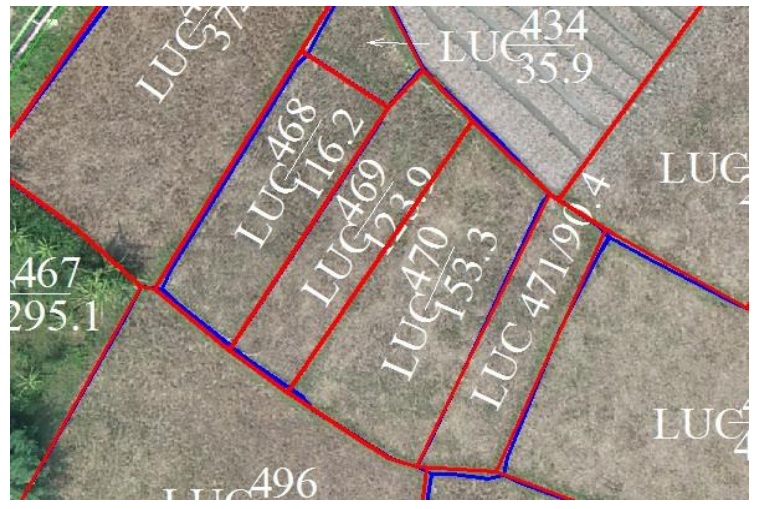

Hình 7. Ranh giới thửa khi so sánh với nền ảnh (màu đỏ là ranh giới thứa vẽ tù̀ dũ liệu ảnh UAV và màu xanh là ranh giới thứa trên bản đồ do Sở TN\&MT cung cấp).

đảm bảo độ chính xác khá cao (Bảng 5), tuy nhiên trong đường ranh thửa nhiều chỗ chưa được đi đúng theo tâm đường bờ (lỗi này chủ yếu là do quá trình đi gương của người đo vẽ theo công nghệ toàn đạc điện tử).

Chính vì vậy, có thể khẳng định việc sử dụng dữ liệu ảnh UAV cho thành lập bản đồ đất thổ canh hoàn toàn đảm bảo được độ chính xác theo tỷ lệ bản đồ 1:2000 của khu vực thực nghiệm, ngoài ra 
còn đảm bảo tốt hơn cho đường ranh thửa bởi được số hóa theo đúng tâm đường bờ.

\section{Kết luận và kiến nghị}

Trên cơ sở đo vẽ bản đồ địa chính khu vực thực nghiệm bằng công nghệ UAV và tiến hành so sánh, đánh giá độ chính xác của bản đồ thực nghiệm với bản đồ địa chính chính quy do Sở TN\&MT cung cấp có thể thấy được tính ư việt của dữ liệu UAV trong thành lập bản đồ đất thổ canh.

Kết quả nghiên cứu thực nghiệm cho thấy bản đồ đất thổ canh được thành lập từ dữ liệu ảnh chụp UAV có thể đáp ứng tốt yêu cầu về độ chính xác trong đo vẽ bản đồ địa chính (phần đất thổ canh) ở Việt Nam theo quy phạm hiện hành. Tuy nhiên, để có thể triển khai được trong thực tiễn cần thiết phải có những nghiên cứu và đánh giá toàn diện hơn cho nhiều dạng địa hình đồng thời xây dựng các văn bản chính quy quy định về các chỉ tiêu kỹ thuật cụ thể khi áp dụng phương pháp này trong thành lập bản đồ địa chính (phần đất thổ canh).

\section{Những đóng góp của tác giả}

Bùi Ngọc Quý (Tác giả chính, tác giả liên hệ) Mục đích nghiên cứu, phạm vi nghiên cứu, phương pháp và các kết quả đạt được;

Phạm Anh Tuấn, Dương Anh Quân, Phạm Văn Hiệp, Trần Trung Kiên, Hoàng Xuân Tứ, Nguyễn Đại Đồng, Nguyễn Danh Đức - Phương pháp luận, phân tích dữ liệu;

Nguyễn Việt Hưng - Kiểm chứng, điều tra khảo sát.

\section{Tài liệu tham khảo}

Bộ Tài nguyên và Môi trường, (2014). Thông tư số 25/2014/TT-BTNMT ngày 19/05/2014 của Bộ Tài nguyên và Môi trường quy định về bản đồ địa chính.

Bùi Ngọc Quý, Phạm Văn Hiệp, (2017). Nghiên cứu xây dựng mô hình 3D từ dữ liệu ảnh máy bay không người lái (UAV). Tạp chí Khoa học Kỹ thuật Mỏ - Địa chất 58(4), 201 - 211.

Bùi Ngọc Quý, Phạm Văn Hiệp, (2018). Xây dựng mô hình 3D dạng tuyến phục vụ thiết kế đường điện cao thế 220 Khu vực Mê Linh - Bá Thiện từ dữ liệu ảnh chụp UAV. Hội nghi toàn quốc Khoa học Trái đất và Tài nguyên với phát triển bền vững - ERSD 2018, 91 - 96.

Bùi Tiến Diệu, (2016). Xây dựng mô hình số bề mặt và bản đồ trực ảnh sử dụng công nghệ đo ảnh máy bay không người lái (UAV). Hội nghi Khoa học: Đo đạc Bản đồ với úng phó biến đổi khí hậu.

Bui Xuan Nam, Lee Chang woo, Nguyen Quoc Long, Adeel Ahmad, Cao Xuan Cuong, Nguyen Viet Nghia, Le Van Canh, Nguyen Hoang, Le Qui Thao, Duong Thuy Huong, Nguyen Van Duc, (2019). Use of Unmanned Aerial Vehicles for 3D topographic Mapping and Monitoring the Air Quality of Open-pit Mines. Inżynieria Mineralna 21, 223 - 239.

Cao Tiến An, (2010). Vai trò của đo đạc bản đồ địa chính trong công tác quản lý đất đai. Tạp chí Tài nguyên và Môi trường 2, 41 - 44.

Kenneth David Mankoff, Tess Alethea Russo, (2013). The Kinect: a low-cost, high-resolution, short-range 3D camera. Earth Surface processes and Landforms 38, 926 - 936.

Le Van Canh, Cao Xuan Cuong, Le Hong Viet and Dinh Tien, (2020). Volume computation of quarries in Vietnam based on Unmanned Aerial Vehicle (UAV) data. Journal of Mining and Earth Sciences 61(1), 21 - 30. DOI:https://doi.org/10.46326/JMES.2020.61 (1). 03.

Nguyen Quoc Long, Bui Xuan Nam, Cao Xuan Cuong, Le Van Canh, (2019). An approach of mapping quarries in Vietnam using low-cost Unmanned Aerial Vehicles. Journal of Mining and Earth Sciences 11(2), 199 - 210. DOI:10.21177/1998-4502-2019-11-2-199210.

Nguyễn Viết Nghĩa, (2020). Xây dựng mô hình số độ cao cho mỏ lộ thiên có độ sâu lớn từ dữ liệu ảnh chụp bằng thiết bị bay Inspire 2. Tạp chí Khoa học Kỹ thuật Mỏ -Đị chất 61(1), 1 - 10.

Phạm Ngọc Lãng, (2015). Nghiên cứu thử nghiệm máy bay không người lái UAV để chụp ảnh địa mạo, thổ nhưỡng, hiện trạng sử dụng đất và hiện trạng mặt nước khu vực thành phố Đà Lạt (Lâm Đồng) và các cùng phụ cận phục vụ bảo vệ môi trường. Nhiệm vụ nghiên cúu khoa học cấp nhà nước, chương trình Tây nguyên 3. 
Sebastian S., Jochen T., (2014). Mobile 3D mapping for surveying earthwork projects using an Unmanned Aerial Vehicle (UAV) system. Automation in Construction 41, 1 - 14.

Sona, G., Pinto, L., Pagliari, D., Passoni, D., Gini, R., (2014). Experimental analysis of different software packages for orientation and digital surface modelling from uav images. Earth Science Informatics 7, 97 - 107.
Turner, D., Lucieer, A., and Watson, C., (2012). An automated technique for generating georectified mosaics from ultra-high resolution unmanned aerial vehicle (UAV) imagery, based on structure from motion (SfM) point clouds. Remote Sensing 5, 1392 1410. 